\title{
DEL JURAMENTO O PROMESA DE ACATAR LA CONSTITUCIÓN EN EL ÁMBITO PARLAMENTARIO
}

ALBERTO ANGUITA SUSI 
SUMARIO:

I. INTRODUCCIÓN. II. TRASCENDENCIA JURÍDICA. III. RELEVANCIA DE LA FÓRMULA EMPLEADA. IV. ¿MANTENER O ELIMINAR EL REQUISITO DEL JURAMENTO O PROMESA? V. CONCLUSIONES. 


\title{
DEL JURAMENTO O PROMESA DE ACATAR LA CONSTITUCIÓN EN EL ÁMBITO PARLAMENTARIO
}

\author{
ALBERTO ANGUITA SUSI \\ Profesor Titular de Derecho Constitucional ${ }^{1}$ \\ (Universidad de Jaén)
}

\section{INTRODUCCIÓN}

Desde tiempos inmemoriales la toma de posesión de los cargos públicos se ha visto rodeada de una serie de formalismos cuyo fin es dar solemnidad y publicidad a dichos actos. Uno de los requisitos que forman parte de este ritual es el juramento (o promesa), en virtud del cual se externaliza el compromiso de cumplir debidamente las funciones propias del cargo frente a la ciudadanía ${ }^{2}$.

El juramento puede ser definido genéricamente como «el compromiso, asumido de forma expresa y solemne mediante la apelación a valores éticos profusamente difundidos y compartidos en la comunidad, conforme un rito y una fórmula prefija-

1 Profesor Titular de Derecho Constitucional. Departamento de Derecho Público. Universidad de Jaén. Campus Las Lagunillas s/n. Edificio Ciencias Sociales y Jurídicas (D3). 23071 Jaén. Email: aanguita@ujaen.es ORCID ID: https://orcid.org/0000-0001-8777-7346

2 Como señalaba la STC 119/1990, «el requisito del juramento o promesa es una supervivencia de otros momentos culturales y de otros sistemas jurídicos a los que era inherente el empleo de ritos o fórmulas verbales ritualizadas como fuentes de creación de deberes jurídicos y de compromisos sobrenaturales».

El juramento se sustentaba en la vulnerabilidad y las limitaciones humanas a la hora de comprometerse con la realización de ciertos actos, lo que explica la formulación de un compromiso formal ante la divinidad, que no emite un juicio. Sirva como ejemplo el juramento de los diputados en la sesión constitutiva de las Cortes de Cádiz, de 24 de septiembre de 2010, cuya fórmula sería consagrada por el art. 117 de la Constitución de 1812. Para mayor abundamiento véase el trabajo de LORENTE M., «El juramento constitucional», Anuario de Historia del Derecho, n 65, 1995, pp. 589 a 596. En palabras de esta autora podría decirse que en aquélla época el juramento era el «instrumento religioso a través del cual se expresaba el deber -del súbdito católico- de obediencia sin restricción alguna a cualquier poder establecido» (pág. 595). La alternativa al juramento sería la promesa, de corte más secular, tal y como preveía el art. 72 de la Constitución de 1931, en virtud del cual: «El Presidente de la República prometerá ante las Cortes, solemnemente reunidas, fidelidad a la República y a la Constitución».

(C) UNED. Revista de Derecho Politico

N. ${ }^{\circ} 109$, septiembre-diciembre 2020, págs. 329-342 
dos, de seguir en el futuro un comportamiento inspirado en la fidelidad y lealtad respecto a los deberes de orden general o particular» ${ }^{3}$.

Ahora bien, si el juramento o promesa es el instrumento para manifestar la voluntad de los cargos y representantes políticos de cumplir con las obligaciones respectivas $^{4}$, la pregunta empleada debe ser aséptica y neutral, evitando las referencias a compromisos que excedan el estricto deber de cumplir el ordenamiento jurídico.

En este sentido, y pese que el «acatamiento de la Constitución» exigido en la fórmula de juramento o promesa a los actuales parlamentarios, no implique una identificación o adhesión ideológica e incondicionada a los valores que dicha norma propugna ${ }^{5}$, el término «acatamiento ${ }^{6}$, al igual que sucedería con el de fidelidad y lealtad ${ }^{7}$, podría ser entendido como una especie de «cláusula conminatoria o coercitiva»; de aquí la conveniencia de su sustitución por el de «cumplimiento», más objetivo y acorde con el mandato del art. 9.1 CE.

Sobre esta cuestión, la STC 119/1990 señalaba que «en un Estado democrático que relativiza las creencias y protege la libertad ideológica; que entroniza como uno de sus valores superiores el pluralismo político; que impone el respeto a los representantes elegidos por sufragio universal en cuanto poderes emanados de la voluntad popular, no resulta congruente una interpretación de la obligación de prestar acatamiento a la Constitución que antepone un formalismo rígido a toda otra considera-

${ }^{3}$ CASTAÑÓN JIMÉNEZ C., Régimen jurídico y práctica del juramento en España, CEPC, Madrid, 2017, pág. 29. Definición que la autora recoge a su vez de Árdal P.S., tal y como se cita en la nota a pie $\mathrm{n}^{\mathrm{o}} 3$ de dicha página.

${ }^{4}$ El juramento es «el único elemento estrictamente jurídico de la fórmula estereotipada» (DE MENDIZÁBAL ALLENDE R., «El juramento o promesa de acatamiento de la Constitución», Actualidad Administrativa, no 2, 2016, pág. 8).

5 Tal y como apunta DIAZ REVORIO, «la sujeción y acatamiento a la Constitución no supone un pronunciamiento ideológico pues dentro de la Norma fundamental caben las más variadas ideologías; pero esto supondría desconocer que la Constitución tampoco es totalmente neutral en el terreno ideológico o político, sino que más bien establece importantes principios» («El acatamiento a la Constitución y el acceso al ejercicio de cargos públicos representativos», Revista de las Cortes Generales, $n^{\circ} 28,1993$, pág. 141). En esta línea, CASTAÑÓN JIMÉNEZ entiende que «el hecho de que el juramento parlamentario se presente en el ordenamiento como un requisito objetivo, no significa necesariamente que no encubra en realidad un requisito ideológico y, por tanto, una barrera o un obstáculo a la participación» («El juramento parlamentario ¿mecanismo de participación o de exclusión? en AAVV (Coord. MORÁN MARTíN R.)., Participación y exclusión política: causas, mecanismos y consecuencias, Tirant lo Blanch, Valencia, 2018, pág. 460).

${ }^{6}$ El juramento lleva aparejado tres aspectos que desde la época medieval se han ido incorporando a su contenido: sometimiento, cumplimiento y acatamiento. Así lo ha señalado APARICIO PÉREZ M., «El acatamiento a la Constitución, requisito de la condición plena de parlamentario», Revista Jurídica de Cataluña, no 4, 1985, pág. 188.

7 Cabría distinguir «entre mecanismos de defensa del sistema democrático, lo que estrictamente debería ser denominado democracia militante, de mecanismos de defensa de la Constitución, o incluso del propio Estado y distinguir así entre lealtad democrática y lealtad constitucional» (CATALÁ I BAS A.H., «Cuestiones controvertidas en torno al juramento o promesa de acatamiento a la Constitución de los cargos representativos», en AAVV (Coord. MARTÍN CUBAS J.)., Constitución, política y administración: España 2017, reflexiones para el debate, Tirant lo Blanch, Valencia, 2017, pág. 221). 
ción, porque de ese modo se violenta la misma Constitución de cuyo acatamiento se trata, se olvida el mayor valor de los derechos fundamentales y se hace prevalecer una interpretación de la Constitución excluyente frente a otra integradora» ${ }^{8}$.

Este razonamiento evidencia que el juramento o promesa posee una importante carga simbólica o ritual, dado que la sujeción al ordenamiento jurídico es consustancial al recto ejercicio del cargo público, por lo que, en principio, carecería de trascendencia jurídica alguna. A esta controvertida cuestión dedicamos el siguiente epígrafe.

\section{TRASCENDENCIA JURÍDICA}

En la STC 119/1990, nuestro máximo interprete constitucional sostenía que «la obligación de prestar juramento o promesa de acatar la Constitución no crea el deber de sujeción a ésta, que resulta ya de lo que dispone su art. 9.1 y aunque pueda entenderse que lo refuerza, creando un vínculo suplementario de índole religiosa o moral, esta vinculación más fuerte en el fuero interno no tiene, como tal, trascendencia jurídica ni es, en consecuencia la finalidad perseguida por la norma legal o reglamentaria que la impone (...) su eventual incumplimiento no priva, en consecuencia, de la condición de diputado o senador, para lo que no hay otro título que la elección popular, sino sólo del ejercicio de las funciones propias de tal condición y, con ellas, de los derechos y prerrogativas anexos».

La afirmación, sostenida por el TC, de que el requisito del juramento o promesa carece de trascendencia jurídica no deja de ser paradójica y contradictoria, toda vez que su incumplimiento priva al parlamentario, reglamentariamente hablando, de poder ejercer el cargo con todas las garantías y derechos inherentes al mismo?.

8 Sobre la jurisprudencia constitucional recaída en esta materia puede verse a SANTAOLALLA LÓPEZ F., «El juramento y los reglamentos parlamentarios (Comentario a la STC 119/1990, de 21 de junio)», Revista Española de Derecho Constitucional, n 30, 1990, pp. 149 a 159; y ROLLNERT LIERN G., «El conflicto entre los deberes parlamentarios y la libertad ideológica ante el Tribunal Constitucional», Corts: Anuario de Derecho parlamentario, $\mathrm{n}^{\circ} 11,2001$, pp. 179 a 200. En cuanto al juramento o promesa de acatar la Constitución en el ámbito local consúltese a COST R., «La «desnaturalización» del juramento o promesa», Consultor de los ayuntamientos y de los juzgados: Revista técnica especializada en administración local y justicia municipal, no 2 (Extra), 2019, pp. 114 a 134.

9 Haciendo un recorrido por la historia de los reglamentos parlamentarios decimonónicos publicados en España puede decirse, en cuanto a la trascendencia del juramento o promesa se refiere, «que su omisión provocaba generalmente las siguientes consecuencias sobre la condición de parlamentario: i) El parlamentario que no juraba, quedaba encuadrado bajo la categoría de electo, en una situación parecida a la de suspensión total y temporal de sus derechos y deberes; ii) El electo carecía de la facultad de votar; y de hecho las mayorías se contabilizaban sobre el número de miembros de la Cámara que habían cumplido el trámite del juramento o promesa. Tampoco se les adscribía a las comisiones que se formasen en las Cámaras, ni se les permitía intervenir oralmente en los debates; iii) El electo, por último, se considera miembro de la Cámara y, consecuentemente, la misma debe conocer y pronunciarse sobre su procesamiento» (MORALES ARROYO J.M., «La determinación del periodo 
La disyuntiva reside pues en determinar la naturaleza del juramento o promesa, es decir, «se trata de examinar si los efectos del mismo son constitutivos de la magistratura a la que van unidos o si, por el contrario, tan solo sirven para perfeccionar la condición de que se trate» ${ }^{10}$. Veamos qué dicen los respectivos Reglamentos parlamentarios al respecto.

El art. 20 del Reglamento del Congreso diferencia entre «diputado electo»y «diputado pleno», de tal manera que la condición plena de diputado, con los derechos y prerrogativas inherentes, quedaría supeditada al requisito reglamentario del juramento o promesa ${ }^{11}$.

El art. 12 del Reglamento del Senado, por su parte, diferencia entre «condición perfecta» y «condición imperfecta» en cuanto al status de los senadores. De hecho, este precepto establece para el segundo caso «la suspensión de los derechos económicos y a la participación del senador en el ejercicio de las funciones constitucionales de la Cámara» ${ }^{12}$.

Podría decirse, al menos semánticamente, que mientras el Reglamento del Congreso considera el juramento o promesa como un requisito previo para adquirir plenamente la condición de diputado, el Reglamento del Senado lo entiende como un requisito para perfeccionar dicha condición. Para los diputados, la ausencia de juramento o promesa afecta tanto al disfrute de los derechos económicos como a las prerrogativas parlamentarias; mientras que para los senadores sólo tendrá efectos económicos e imposibilitará la participación en el ejercicio de las funciones de la Cámara Alta $^{13}$.

Las diferentes consecuencias del juramento o promesa en una y otra Cámara no dejan de resultar paradójicas, dada la idéntica naturaleza jurídica del mandato parlamentario de diputados y senadores. En todo caso, bien entendido, la imposibilidad,

de vigencia del Estatuto de diputados y senadores», Revista de las Cortes Generales, nº 19, 1990, pp. 55 y 56).

10 GUTIÉRREZ VICÉN C., «Juramento o promesa y lealtad a la Constitución», en AAVV (Coords. GONZÁLEZ HERNÁNDEZ E. y RUBIO NÚÑEZ R. / Dir. PENDÁS GARCÍA B.)., España constitucional (1978-2018): trayectorias y perspectivas, Vol. 3º, Tomo 3, CEPC, Madrid, 2018, pág. 1955.

11 Este precepto supondría la aplicación de la denominada, por parte de la doctrina, «teoría del órgano», en virtud de la cual se asimilan los cargos electos a los cargos administrativos y la toma de posesión por la satisfacción del juramento que tendría un carácter constitutivo, lo que equivale a que es la Cámara representativa quien decide la admisión de sus miembros, desvirtuando de esta forma la relación representativa (RODRIGUEZ AGUILERA DE PRAT C. y VERNET LLOBET J., «Cuestiones simbólicas y Constitución Española», Revista de Estudios Políticos, nº 79, 1993, pág. 144).

12 MORALES ARROYO J.M., «La determinación del periodo de vigencia del Estatuto de diputados y senadores», op. cit., pp. 75 y 76.

13 «Es decir, los senadores conservan las prerrogativas de inmunidad e inviolabilidad incluso aunque no presten el juramento o promesa, puesto que se considera que la condición de senador la otorga la condición de electo, y no puede supeditarse a un requisito formal o ideológico» (CASTAÑ́́N JIMÉNEZ, Régimen jurídico y práctica del juramento en España, op. cit., pág. 109). En el mismo sentido puede verse a FERNÁNDEZ-VIAGAS BARTOLOMÉ P., «El juramento de los Diputados y Senadores», Revista General de Derecho, n 504, 1986, pp. 3667 a 3677. 
por parte de estos últimos, de participar en el ejercicio de las funciones parlamentarias (asistencia, debate y votaciones) les privaría fácticamente de las prerrogativas propias de dicho cargo, por lo que la aparente formalidad del juramento o promesa de los senadores resultaría más ficticia que real.

En el plano autonómico las distintas previsiones reglamentarias pueden ser divididas en dos grupos:

a) Los reglamentos de Cataluña y el País Vasco no han previsto el requisito del juramento o promesa, de tal manera que en la sesión constitutiva de sus respectivos plenos la Mesa se limita a verificar el acta de los diputados presentes $^{14}$.

b) El resto de reglamentos parlamentarios prevén, en unos términos prácticamente asimilables, la suspensión de los derechos y prerrogativas del diputado electo en tanto no se produzca la adquisición plena de la condición de parlamentario a través del cumplimiento, entre otros, del requisito del juramento o promesa de acatar la Constitución y el respectivo Estatuto ${ }^{15}$.

14 Aunque en Cataluña se obvia el juramento en sesión plenaria, deberá tener lugar ante el Oficial Mayor, convirtiéndose por tanto en un trámite administrativo. De la misma forma que en Navarra el juramento o promesa se sustancia ante la Mesa. Tomamos estos datos de GUTIÉRREZ VICÉN C., Juramento o promesa y lealtad a la Constitución, op. cit., pág. 1961.

Algo parecido sucede en el caso de las elecciones al Parlamento Europeo, en cuyo art. 3.1 del Reglamento se determina: «Tras las elecciones generales al Parlamento Europeo, el presidente invitará a las autoridades competentes de los Estados miembros a que notifiquen inmediatamente al Parlamento los nombres de los diputados electos, de forma que puedan tomar posesión de sus escaños desde la apertura de la primera sesión que se celebre después de las elecciones». A lo que el párrafo segundo añade en su parte final: «Siempre que hayan firmado previamente la mencionada declaración (de incompatibilidad) por escrito, los diputados tomarán posesión de sus escaños en el Parlamento y en sus órganos con plenitud de derechos, aunque no se hayan comprobado sus credenciales o no se haya resuelto sobre una posible impugnación».

Ahora bien, con carácter previo, en virtud del art. 224.2 de la LOREG, «En el plazo de cinco días desde su proclamación, los candidatos electos deberán jurar o prometer acatamiento a la Constitución ante la Junta Electoral Central. Transcurrido dicho plazo, la Junta Electoral Central declarará vacantes los escaños correspondientes a los diputados del Parlamento Europeo que no hubieran acatado la Constitución y suspendidas todas las prerrogativas que les pudieran corresponder por razón de su cargo, todo ello hasta que se produzca dicho acatamiento». De esta regulación resalta que «la autoridad ante la que se presta es la JEC, y no el presidente del Parlamento Europeo. El plazo se reduce a cinco días desde la proclamación como candidatos electos, y no tres sesiones plenarias. Y, llamativamente, el contenido del juramento o promesa es de acatamiento a la CE, y no a los Tratados de la UE» (CASTAÑÓN JIMÉNEZ C., Régimen jurídico y práctica del juramento en España, op. cit., pág. 120).

15 Dentro de este grupo de regulaciones reglamentarias destaca el art. 7 del Reglamento del Parlamento de Galicia, en virtud del cual los diputados gallegos que no presten el juramento o promesa de acatar la Constitución no por ello pierden la prerrogativa de inviolabilidad e inmunidad que serán efectivas desde su proclamación como electos. Eso sí, a los diputados gallegos se les exige no sólo acatar sino guardar fidelidad a la Constitución, lo que dio pie a un recurso de amparo que fue resuelto en la STC 122/1983, de 16 de diciembre. Aunque los recurrentes entendieron que «guardar fidelidad» suponía una exigencia de tipo ideológico, el TC consideró, en cambio, que dicha cláusula refleja

(C) UNED. Revista de Derecho Politico

N. ${ }^{\circ} 109$, septiembre-diciembre 2020, págs. 329-342 


\section{RELEVANCIA DE LA FÓRMULA EMPLEADA}

La pregunta que se evacúa en el juramento se encontraba regulada originariamente en el art. 1 del Real Decreto 707/1979, de 5 de abril, que se refiere al acto de toma de posesión de cargos o funcionarios públicos de la Administración. En virtud de este precepto, quien haya de dar posesión formulará la siguiente pregunta: «¿Juráis o prometéis por vuestra conciencia y honor cumplir fielmente las obligaciones del cargo (...) con lealtad al Rey, y guardar y hacer guardar la Constitución como norma fundamental del Estado?» ${ }^{16}$

En nuestra opinión, si el juramento o promesa tiene como fin manifestar el compromiso de los cargos representativos de cumplir el ordenamiento jurídico vigente, la fórmula de juramento debería ser la siguiente: ¿Jura o promete cumplir la Constitución? ${ }^{17}$, en lugar de hacer referencia al acatamiento de la norma suprema ${ }^{18}$.

En el plano autonómico la regla general es que el parlamentario prometa o jure acatar la Constitución y el Estatuto correspondiente, a lo que algunos reglamentos parlamentarios (Castilla-La Mancha, Cantabria) añaden la coletilla «y ejercer el cargo de diputado en defensa de los intereses (de los ciudadanos de la Comunidad Autónoma respectiva)». Por su parte, el reglamento de las Cortes de la Comunidad Valenciana añade: $y$ «guardar fidelidad a la Generalitat».

En cuanto a la respuesta empleada en el juramento, la STC 119/1990, señalaba que «para tener por cumplido el requisito no bastaría sólo con emplear la fórmula ritual, sino emplearla, además, sin acompañarla de cláusulas o expresiones que, de una u otra forma, vacien o condicionen su sentido propio». Complementariamente, la STC 74/1991, prohibía que «su formulación desnaturalice o vacíe de contenido el

«simplemente el compromiso de aceptar las reglas del juego político y el orden jurídico existente (...) y a no intentar su transformación por medios ilegales».

Sobre las fórmulas de juramento de los diputados autonómicos puede verse CASTAÑÓN JIMÉNEZ C., Régimen jurídico y práctica del juramento en España, op. cit., pp. 117 y 118. Para el caso de la Comunidad Valenciana, el trabajo de MARTÍNEZ CORRAL J.A. y VISIEDO MAZÓN F., "Juramento para el acceso al pleno ejercicio del cargo de diputado o diputada de las Cortes Valencianas", en AAVV., Casos prácticos comentados de Derecho autonómico valenciano: jurisprudencia y doctrina, Centro de Estudios Delta, Valencia, 2004, pp. 138 a 188.

${ }^{16}$ La STC 8/1995, de 25 de enero, declaró que el requisito del juramento o promesa sólo puede establecerse mediante una norma de rango legal, conforme a lo dispuesto por el artículo 23 de la CE.

${ }^{17}$ CATALÁ I BAS defiende que en la pregunta se contemple el compromiso de respetar y defender los principios democráticos previstos en la Constitución. En nuestra opinión, sin embargo, este tipo de fórmulas tan indeterminadas no eliminaría la discrecionalidad del parlamentario de acuerdo con sus preferencias o concepciones democráticas ( «Cuestiones controvertidas en torno al juramento o promesa de acatamiento a la Constitución de los cargos representativos», op. cit., pp. 225 y 226).

${ }^{18}$ La Resolución de la Presidencia del Congreso de los Diputados, de 30 de noviembre de 1989, sobre la forma en que se ha de prestar el juramento o promesa de acatamiento a la Constitución previsto en los artículos 4 y 20 del Reglamento de la Cámara, determina que dicho requisito se llevará a cabo de la siguiente manera: «El Presidente preguntará al diputado que ha de prestarlo: ¿Juráis o prometéis acatar la Constitución? Dicha pregunta será contestada mediante la expresión "Sí, juro" o "Sí, prometo"». 
acatamiento mismo, mediante fórmulas que supongan un fraude a la ley o priven de sentido al propio acatamiento» (las cursivas son añadidas).

Pese a estos condicionantes, la jurisprudencia constitucional llegó a reconocer que es posible prestar el juramento utilizando una fórmula distinta a «sí juro o sí prometo». Este precedente, unido a la permisibilidad mostrada por las respectivas presidencias de las Cámaras parlamentarias durante los últimos años, ha dado lugar al empleo de toda una serie de imaginables fórmulas.

Cronológicamente hablando puede decirse que es a partir de la XI Legislatura en el Congreso y de la X Legislatura en el Senado cuando algunos diputados y senadores comienzan a jurar y prometer sus cargos haciendo uso de fórmulas de dudosa constitucionalidad. Una tendencia que se ha visto consolidada en la XIII y XIV Legislaturas, las cuales nos han ofrecido todo un muestrario de fórmulas empleadas que pueden ser clasificadas en tres grupos ${ }^{19}$ :

a) Fórmulas que introducen una condición resolutoria. «Sí, prometo por imperativo legal hasta la Constitución Catalana» (Ayast i Bartrina); «Sí, lo prometo por imperativo legal, en espera de la Constitución de la República catalana» (Cortés Ges, Estradé Palau y Pi-Cornell Grenzner); «Por imperativo legal hasta la creación de la República vasca» (diputados de Bildu) ${ }^{20}$.

b) Fórmulas que añaden coletillas o proclamas independentistas. «Por el derecho de autodeterminación, por la libertad de los presos políticos y el retorno de los exiliados» (Riba i Giner); «Por la libertad de los presos y exiliados políticos, por la República catalana» (Bassa Coll); «Con lealtad al mandado democrático del 1 de octubre, por fidelidad al pueblo de Cataluña, por la libertad de los presos políticos y el retorno de los exiliados, por imperativo legal» (Diputados de JxCat).

Los Vocales de la Junta Electoral Central, Andrés Betancor Rodríguez y Antonio Jesús Fonseca, en sendos votos particulares emitidos frente al Acuerdo 527/2019, de 17 de junio, de dicho órgano, entienden que estas expresiones

19 Conviene aclarar que las distintas fórmulas empleadas por los diputados no se hacen constar en el Diario de Sesiones del Congreso de los Diputados, en el que tan sólo se deja constancia del llamamiento de la Mesa a los distintos diputados para que procedan a jurar o prometer sus cargos. De ahí que hayamos extraído las fórmulas empleadas de la prensa. En cambio, en el Diario de Sesiones del Senado sí se da cuenta de la transcripción de la fórmula empleada por cada senador (Vid. como ejemplo, el Diario de Sesiones del Senado no 1 , de 3 de diciembre de 2019, pp. 14 a 56).

Esta misma práctica se repite en el caso del Parlamento de Andalucía, en el que se transcriben los juramentos individualizados de los distintos diputados llamados a tales efectos. Véanse los Diarios de Sesiones del Parlamento de Andalucía n $n^{\circ}$, de 19 de abril de 2012 (IX Legislatura), pp. 11 y 12; de 16 de abril de 2015 (X Legislatura), pp. 45 a 70; y de 27 de diciembre de 2018 (XI Legislatura), pp. 28 a 58.

${ }^{20}$ El Acuerdo 527/2019, de la Junta Electoral Central, en su reunión de 17 de junio de 2019, tras las elecciones al Parlamento Europeo, de 26 de mayo de 2019, declaró admisible y conforme a la jurisprudencia constitucional la fórmula «Desde mis principios republicanos, hasta la consecución de la república vasca». En este sentido, pueden verse también los Acuerdos de 2 de julio de 1995, 19 de septiembre de 2001, 13 de julio de 2005, 1 de julio de 2014 y 22 de marzo de 2017.

(C) UNED. Revista de Derecho Político

N. ${ }^{\circ} 109$, septiembre-diciembre 2020, págs. 329-342 
no son neutras jurídicamente, ni válidas a los efectos de la incondicionalidad y la plenitud exigidos por la jurisprudencia constitucional, de ahí que defiendan la invalidez de dichos juramentos o promesas.

c) Fórmulas que añaden coletillas reivindicativas y extravagantes. Como puede imaginarse son muchos los ejemplos ${ }^{21}$ :

«Prometo acatar la Constitución y trabajar para cambiarla. Por la soberanía del pueblo, por una España nueva, por la fraternitat entre els pobles. Nunca más un país sin su gente y sin sus pueblos» (Errejón); «Lo juro como catalán y orgullosamente español»(García Albiol); «Me comprometo a luchar por el cumplimiento de los derechos humanos de Andalucía, España y la humanidad, por encima de cualquier otro interés y bajo esta premisa, prometo acatar la Constitución» (Mora); «Sí, prometo para poner las instituciones al servicio de la gente y devolver al pueblo la actividad del Gobierno» (Espinar); «Trabajar para erradicar barreras que provocan desigualdades y atentan contra los derechos humanos, a través de un uso participativo y transparente de esta institución pública» (Lima); «Por un nuevo tiempo feminista de igualdad, libertad y fraternidad» (Freixanet Mateo); «Por la igualdad de género, por la justicia climática y porque los niños tengan un futuro mejor» (Vilá); «Por la España vaciada» (Teruel Existe).

El uso de estas fórmulas, al igual que sucede con las proclamas independentistas, también podría ser tildado de inapropiado dado que vacía de contenido el sentido del juramento. Con ello queremos poner de manifiesto que la valoración de la fórmula empleada no puede sustentarse en el contenido independentista o no de la misma ${ }^{22}$.

${ }^{21}$ En el ámbito parlamentario autonómico también hay ejemplos de fórmulas que introducen añadidos, tales como las siguientes extraídas de los Diarios de Sesiones del Parlamento de Andalucía: «Me comprometo a luchar por recuperar la dignidad del pueblo andaluz y por ser la voz de las personas de Andalucía»; «Viva Andalucía libre»; «Y me comprometo a trabajar por una Andalucía soberana, libre de desahucios, de paro y de transgénicos»; «Y me comprometo a trabajar porque la legislación reconozca como prioridad absoluta la garantía de los derechos humanos en lugar del pago de la deuda a la banca»; "Y prometo luchar por la consecución de una Andalucía soberana, feminista, igualitaria, mestiza, ecologista y libre»; «Comprometiéndome a luchar por el uso social de la tierra y su justa distribución, y por la soberanía alimentaria»; «Y prometo defender a las personas más débiles de esta tierra frente a la cobardía del racismo, de la xenofobia, de la transfobia, de la homofobia y del machismo». Aunque, sin lugar a dudas, la fórmula que se lleva la palma fue la empleada por Sánchez Gordillo que afirmaba: «Por imperativo legal, prometo y me comprometo a luchar con todas mis fuerzas por subvertir el sistema que produce paro, emigración, corrupción, que es el sistema capitalista de producción. Por eso me declaro insumiso ante la dictadura del mercado, sus recetas y sus mandatos. Me comprometo también a luchar con todas mis fuerzas por esta nación sin soberanía que es Andalucía. Me comprometo también a dar voz a los que no tienen voz en este Parlamento y en la calle. Viva Andalucía libre» (Diario de Sesiones del Parlamento de Andalucía n ${ }^{\circ}$, de 19 de abril de 2012, pág. 11).

22 En el Acuerdo de 13 de junio de 2014, la Junta Electoral Central consideraba, en el ámbito de las elecciones al Parlamento Europeo, que la promesa del candidato Pablo Iglesias, que empleaba la fórmula «sí, prometo hasta que los ciudadanos de mi país la cambien para recuperar la soberanía y los derechos sociales», era acorde a la jurisprudencia constitucional. De la misma forma opinaba este órgano, 


\section{IV. ¿MANTENER O ELIMINAR EL REQUSITO DEL JURAMENTO O PROMESA?}

La polémica suscitada en los últimos años en torno a las fórmulas de juramento o promesa utilizadas por los diputados y senadores, además de por otros cargos representativos (como parlamentarios autonómicos y concejales), hace que debamos reflexionar sobre el mantenimiento o la eliminación de este requisito.

La opción de mantener el juramento o promesa implicaría, a su vez, una doble posibilidad: a) Adoptar una postura flexible y permisiva, acorde con la libertad de expresión de los electos, de tal forma que éstos pudieran elegir la fórmula de juramento o promesa que estimaran conveniente, más allá de los límites marcados por la jurisprudencia constitucional ${ }^{23}$; o b) Exigir a los representantes que se aferren a su estricto cumplimiento: es decir, que utilicen la fórmula vigente sin más añadidos, proclamas o condicionamientos ${ }^{24}$. Un cumplimiento que debería hacerse efectivo, ad hoc, por las respectivas presidencias de las Cámaras en la sesión constitutiva ${ }^{25}$.

en la sesión celebrada el 25 de marzo de 2015, cuando la candidata Torres Martínez prometió su cargo en los mismos términos.

En cambio, en el Acuerdo de 27 de octubre de 2011, relativo al juramento de una concejala del Ayuntamiento de la Vall d'en Bas (Girona), la Junta Electoral Central, ante la fórmula de «prometo por imperativo legal respetar la Constitución del Reino de España y el Estatuto de Autonomía de Catalunya con el objetivo de derogarlos para la constitución del Estado independiente de la República de Catalunya», llegaba a la conclusión de que esta promesa resultaba improcedente «porque las expresiones empleadas (...) desnaturalizan el cumplimiento del requisito impuesto por el art. 108.8 LOREG, en la medida en que cabe entenderla como una reserva, limitación o condición del compromiso de respeto a la Constitución». Tomamos estos datos de GUTIÉRREZ VICÉN C., «Juramento o promesa y lealtad a la Constitución», op. cit., pág. 1967.

${ }^{23}$ La Presidente del Senado afirmaba en la sesión constitutiva de esta Cámara: «En relación con la cuestión que plantea en esta sesión, la Mesa de la Diputación Permanente examinó en el día de ayer su escrito sobre fórmulas de acatamiento a la Constitución; y, como bien sabe, esto ya se resolvió en la anterior Legislatura: recuerde que hubo unos acuerdos adoptados por la Mesa de esta Cámara y que se resolvió que dichas fórmulas en ningún momento suponen una contravención a la Constitución ni al Reglamento ni a lo dispuesto en la Sentencia 74/1991 del Tribunal Constitucional» (Diario de Sesiones del Senado $\mathrm{n}^{\circ} 1$, de 3 de diciembre de 2019, pág. 14).

${ }^{24}$ Como señala CASTAÑÓN JIMÉNEZ: «En el acto de juramento o promesa de lo que se trata es de que los ciudadanos puedan comprobar que sus representantes se comprometen individual y solemnemente a desempeñar su mandato desde el acatamiento constitucional» (Régimen jurídico y práctica del juramento en España, op. cit., pág. 128).

25 El Grupo parlamentario popular presentó en septiembre de 2019 una proposición para reformar el Reglamento del Congreso de los Diputados. Concretamente proponía una nueva redacción del art. 4.1 en los siguientes términos: «1. (...) Para realizar el acatamiento de la Constitución el Presidente electo pronunciará la siguiente fórmula dirigiéndose a los Diputados: "¿Juráis o prometéis acatar la Constitución?» Dicho juramento o promesa se prestará por los Diputados únicamente respondiendo «Sí, lo juro» $\mathrm{o}$ «Si, lo prometo», sin que en modo alguno pueda preceder ni proseguir ninguna otra expresión a dicha afirmación». En concordancia con esta previsión, los proponentes defendían la siguiente redacción para el art. 20.3: «Prestar, en la primera sesión del Pleno a que asista, la promesa o juramento de acatar la Constitución, utilizando para ello, única y estrictamente la declaración establecida en el artículo 4.1.»

(C) UNED. Revista de Derecho Político

N. ${ }^{\circ} 109$, septiembre-diciembre 2020, págs. 329-342 
La segunda opción, eliminar el juramento o promesa, nos parece la más acertada por los siguientes motivos: a) Se trata de un requisito no previsto expresamente por la Constitución, sino por el art. 108.8 de la LOREG y los reglamentos parlamentarios; b) No existe una clara voluntad por parte de las presidencias parlamentarias de exigir su estricto cumplimiento; y c) No debe erigirse en una condición constitutiva de la condición plena y efectiva de parlamentario, desvirtuando los fundamentos del mandato representativo.

En consecuencia, la constitución de las asambleas parlamentarias debería hacerse de acuerdo con el procedimiento, plenamente válido y constitucional, seguido en el País Vasco, en el que se obvia el simbólico juramento o promesa y se resalta la elección como el momento constitutivo de la relación representativa ${ }^{26}$.

\section{CONCLUSIONES}

Si bien es cierto que los formalismos forman parte de la simbología y la liturgia jurídica y política, también lo es que con el transcurso del tiempo han perdido parte de su utilidad e idiosincrasia. El trasfondo ritual y taumatúrgico que tenía antaño la toma de posesión de los parlamentarios no tiene sentido en las actuales democracias, donde la legitimidad proviene de las urnas.

(Boletín Oficial de las Cortes Generales, Congreso de los Diputados, Serie B, n 73-1, de 13 de septiembre de 2019, pág. 4).

El mismo grupo parlamentario renovaba la proposición de reforma del Reglamento del Congreso de los Diputados en diciembre de 2019, que unos términos prácticamente similares la primera proposición, pero de una forma un poco más concreta incluía un tercer apartado para el art. 4 con el siguiente tenor literal: «Efectuado por cada uno de los diputados el acatamiento conforme a lo previsto en el apartado anterior, el Presidente le comunicará si ha adquirido la condición plena de Diputado» (Boletín Oficial de las Cortes Generales, Congreso de los Diputados, Serie B, n 24-1, 20 de diciembre de 2019, pág. 3). El debate sobre la toma en consideración de esta última proposición de reforma puede verse en el Diario de Sesiones del Congreso de los Diputados n ${ }^{\circ}$, de 18 de febrero de 2020, pp. 6 a 20.

Hay que señalar, asimismo, que los grupos parlamentarios Vox, Popular y Ciudadanos presentaron en su momento reclamaciones ante la Mesa del Congreso contra el juramento de algunos diputados; las cuales se han materializado en sendos recursos de amparo ante el TC que deberá pronunciarse al respecto. A la espera de ese momento, nos referimos a las últimas noticias filtradas en la prensa sobre la situación en la que se encuentran dichos recursos. Así, en el El País, de 11 junio de 2020, puede leerse que seis magistrados consideran que este asunto tiene especial relevancia y han presentado un escrito para que sea llevado al pleno del TC. Por su parte, el otro grupo de magistrados entienden que no cabe admitir los recursos presentados por constituir lo que se denomina «contraamparos»; esto es, recursos que no persiguen obtener el amparo ante una vulneración de los derechos fundamentales de la que haya sido víctima el recurrente, sino para cuestionar un supuesto mal uso de esos mismos derechos por parte de un tercero.

${ }^{26}$ Cuestión distinta será que tras la toma de posesión el parlamentario no cumpla con los deberes propios del cargo, en cuyo caso entraría en juego la aplicación de las correspondientes medidas disciplinarias previstas en el Reglamento parlamentario. 
La mejor forma de evitar que los rituales se banalicen, tal y como ha sucedido en las últimas sesiones constitutivas de las Cortes y otros organismos representativos, es huir de la parafernalia y que los electos entreguen en el registro de la cámara correspondiente su credencial como parlamentarios: único y verdadero título que les debería habilitar para ejercer con plenitud los derechos y prerrogativas propias del cargo.

Dicho de otra forma: el juramento o promesa de los parlamentarios no los convierte en tales sino que ya lo son, de ahí que no sean elegidos por los Cámaras respectivas sino que, sencillamente, juran ante ellas.

La vinculación jurídica que consagra el art. 9.1 de la Constitución podría resultar incompatible con la introducción, en un plano legal y reglamentario, de un requisito formal e ideologizado que podría poner en entredicho el contenido y la esencia de los principios constitucionales que sustentan el mandato representativo ${ }^{27}$.

Title:

Of the oath or promise to observe the constitution at the parliamentary level.

\section{Summary:}

I. Introduction. II. Legal Transcendence. III. Relevance of the formula used. IV. Maintaining or eliminating the requirement of the oath or promise? V. Conclusions.

\section{Resumen:}

La introducción, en el ámbito legal y reglamentario, del requisito del juramento o promesa para adquirir la plena condición de parlamentario ha suscitado en los últimos años una interesante polémica dado que este trámite, cuya trascendencia jurídica y política es discutible, ha sido utilizado por los parlamentarios para llevar a cabo proclamas y reivindicaciones de todo tipo, desvirtuándose de esta forma los límites constitucionales

${ }^{27}$ En sentido contrario a nuestra postura CASTAÑÓN JIMÉNEZ considera que el cumplimiento generalizado y estricto del requisito del juramento o promesa constituye una garantía del principio de igualdad en cuanto al acceso a la plena condición de parlamentario de todos los representantes de la soberanía nacional (Régimen jurídico y práctica del juramento en España, op. cit., pág. 129). En la misma línea MARTÍN-RETORTILLO BAQUER defiende que el juramento o promesa supone un compromiso público de respeto del ordenamiento jurídico vigente por encima de cualquier idea o aspiración, según un sistema normalizado y generalizado («Acatamiento, lealtad, respecto», Revista Española de Derecho Administrativo, $\mathrm{n}^{\circ} 117,2016$, pág. 22).

(C) UNED. Revista de Derecho Politico

N. ${ }^{\circ} 109$, septiembre-diciembre 2020, págs. 329-342 
marcados por el Tribunal Constitucional en cuanto al cumplimiento de este requisito.

\section{Abstract:}

The introduction, in the legal and regulatory field, of the requirement of the oath or promise to acquire full parliamentary status has generated in recent years an interesting controversy since this procedure, whose legal and political significance is debatable, has been used by the parliamentarians to carry out proclamations and claims of all kinds, thus distorting the constitutional limits set by the Constitutional Court regarding compliance with this requirement.

\section{Palabras clave:}

Juramento, promesa, parlamentario, fórmula.

Key words:

Oath, promise, parliamentary, formula 